\title{
A Case Study of Interpretation Learning Strategies Employed by Successful Interpretation Learners
}

\author{
Sainan Li \\ Faculty of Foreign Language, Huaiyin Institute of Technology, Huaian, China
}

\begin{abstract}
This study was undertaken to find out the interpretation learning strategies employed by successful interpretation learners to achieve the completeness of interpretation. The results showed that, to achieve the completeness of interpretation, they employed knowledge-accumulation, summarization, note-taking and logical-analysis learning strategies, among which the first three learning strategies were employed by all the three subjects, which indicates that in the process of interpretation learning, they all give priority to content or meaning over form or language. The significance of this study is to enrich the existing interpretation learning strategies and provide future interpreters with some interpretation learning strategies to choose from.
\end{abstract}

Index Terms - interpretation learning strategies, successful interpretation learners, completeness

\section{INTRODUCTION}

Given the low passing rate of Advanced Interpretation Test taken by undergraduate students, the researcher did a survey, in which students complained that they could not catch up with the speaker in interpretation and had little time to take notes. The research aims to conduct a case study to probe into the interpretation learning strategies employed by successful interpretation learners. The significance of the study goes as follows: theoretically, seldom scholars have ever been engaged in the field of interpretation learning strategies. The researcher attempted to summarize interpretation learning strategies based on Bao's criteria of interpretation (2005), which is a tentative study to provide some new insights into interpretation learning strategies and enrich the existing theories; practically, the study provides some interpretation learning strategies for future learners to choose from

\section{LITERATURE REVIEW}

This part consists of three sections, namely, the definition of successful interpretation learners, criteria of interpretation, and the previous studies related to interpretation learning strategies.

\section{A. Definition of Successful Interpretation Learners}

In this study, successful interpretation learners are considered to be interpretation learners who have successfully passed Advanced Interpretation Test, which is one of the training programs for talents in short supply and is considered one of the most authoritative tests in examining the command of interpretation.

As is reported, in June 1995, when Advanced Interpretation Test held for the first time, there were 704 people taking the exam, while in September 2002, the number grew up to 21800 and most of the candidates have been to college, even many got doctor or master degree (Hua, 2002). A public survey conducted by an authoritative media in Shanghai indicated that in the top ten qualification certificates college students desired to obtain, foreign language interpretation qualification certificates ranked the third, especially Certificate of Advanced Interpretation Test, which was considered the most authoritative one by foreign-funded enterprises and foreign organizations. However, despite the high participation rate, only $10 \%$ of the candidates could pass the test and get the certificate (Xie, 2001).

Thus, taking high difficulty and low pass rate of Advanced Interpretation Test into consideration, interpretation learners who have passed this test are successful interpretation learners.

\section{B. Criteria of Interpretation}

With the same situation as translation criteria, there is no unified criterion for interpretation, which could be perceived differently in terms of different perspectives and considerations. Xiamen University's assessment for interpretation test assesses interpretation from the completeness, accuracy, language expression, fluency and speed, clarity and resilience of information conversion (Guo, Lin, 1996); C. S. Yang in Fu Jen Catholic University in Taiwan made her interpretation professional test scoring table from the four evaluation criteria of loyalty, expression, language and time control (Yang, 2005); H. P. Liu listed speed of response, understanding, expression and mental qualities as interpretation criteria (Liu, 2005); according to Chen, interpretation evaluation should cover interpreters' abilities of knowledge, techniques and mentality (Chen, 2002); Ren proposed criteria of accuracy, fluency and quickness for 
interpretation (Ren, 2009); Bao (2005) proposed criteria of interpretation in his monograph An Overview of Interpretation Theory as completeness, accuracy and fluency.

Apart from these, criteria of Advanced Interpretation Test go as follows: 1) Interpretations with complete and accurate content (without missing or misinterpretations), correct pronunciation and intonation, fluently expression and error-free language are rated excellent. 2) Interpretations with almost complete and accurate content (without significant missing or misinterpretations), basically correct pronunciation and intonation, almost fluently expression and without significant error in language are rated passed. 3) Interpretations without complete and accurate content (with one third missing or misinterpretations or more), with errors in pronunciation and intonation, without fluent expression and with errors in language are rated failed.

As far as all of these criteria are concerned, the researcher considered Bao's criteria of interpretation are the most comprehensive ones and are happened to coincide with the criteria of Advanced Interpretation Test. It is on this basis that the researcher categorized interpretation learning strategies. Bao, a professor in Beijing International Studies University, whose research specialty is interpretation theory and teaching, published several monographs and papers during his lifetime. In his monograph An Overview of Interpretation Theory, he proposed interpretation criteria of completeness, accuracy and fluency. Based on a survey made by the researcher, most of the students believe completeness is the most difficult to achieve. According to Bao (2005), completeness refers to comprehensive and full interpretation of the main points of the contents, original intention and connotation in the original language. It is aimed at the content of the original language, bringing up requirement of "main point interpretation" for interpreters, with the purpose of solving the methodological problem on how to make choices among different content information. This criterion on content requires an interpretation of complete and faithful, without addition or subtraction, and the basic unit of meaning is on discourse level. In other words, interpreters should interpret all the units of meaning correctly, which could thus be regarded as completeness.

\section{Previous Studies on Interpretation Learning Strategies}

Based on a thorough and comprehensive survey related to this study, the author found that there were no special books or journals concerned with interpretation learning strategies other than three academic theses. Some books and journals gave some suggestions on interpretation techniques and strategies, which the author considered of great value for this study to some extent.

Previous studies of interpretation strategies are covered in a broad sense both in fields and dimensions. The researcher used to make a review on the previous studies and put the interpretation strategies into five categories on different dimensions: studies on interpretation strategies concerning theories, texts, contexts, process and teaching respectively $(\mathrm{Li}, 2013)$.

In terms of the only three academic theses concerning interpretation learning strategies, two of them are Master's theses. One is written by Zheng (2004), a graduate of Sichuan University, on the title of "On Interpretation Strategies------From the Perspective of SLA", which raised two research questions concerning the overall pattern of ILS in a broader sense and specific interpretation strategies in their interpretation learning process employed by the university English majors. He adopted a top-down method of research that classified the ILS on the basis of O'Malley \& Chamot's model, namely metacognitive strategies, cognitive strategies and social/affective strategies, under each of which there are several specific strategies. A questionnaire involved the totally ten specific strategies is conducted with three alternatives for each question, and the students are supposed to choose only one among the three. The results demonstrate that almost all the participants view interpretation learning interesting and derive much pleasure and sense of success from it. All the strategies are employed among which, the most frequently used ones are direct advance organization, plan-making-and-plan-implementing and indirect advance organization.

Another Master's thesis “A Case Study of the Effectiveness of Interpretation Learning Strategies” written by Q. Yang (2006) from Dong Hua University is based on Zheng's research. He further examined the effectiveness of interpretation learning strategies and interpretation strategy training. The results illustrated that most of the students showed a positive attitude towards ILS training, through which they gained some improvement in interpretation skills.

Lei's (2011) "Conceptual Dimension Construction and Empirical Assessment of Learning Strategy for Interpreting" is a journal paper that constructed a conceptual model with four dimensions for interpretation learning strategies, namely cognitive strategy, compensation strategy, social strategy and affective strategy and adopted empirical research methods to assess the reliability in the concept meter, exploratory factor analysis and confirmatory factor analysis.

Based on the above literature review, it can be seen that despite the lack of professional interpreters and the increasing number of people learning interpretation, there are seldom monographs or papers related to interpretation learning strategies. The three papers mentioned above are all top-down researches by constructing a model and evaluating it afterwards.

Studies of interpretation strategies, which sound similar to interpretation learning strategies, are covered in a broad sense concerning theories, texts, contexts, process and teaching, both theoretically and empirically, among which the researchers tend to focus more on interpretation strategies concerning contexts, that is, investigating the strategies in a particular field, such as conference interpretation strategies, touristic interpretation strategies, ceremony interpretation, etc, and most of studies are subjective and experiential without theoretical basis and scientific methodology. Even though, they may shed lights on interpretation learning to some extent. 


\section{Methodology}

This part consists of two sections. The first section addresses research questions. The second section describes the research design that consists of the subject, the instrument, interview guide, data collection, data analysis and ethical issues.

\section{A. Research Questions}

This study aims to investigate the learning strategies employed by successful interpretation learners to achieve the completeness of interpretation. The research question is therefore addressed as: what interpretation learning strategies are employed by successful learners to achieve the completeness of interpretation?

\section{B. Research Design}

The research design involved subjects, instruments, interview guide, data collection, data analysis and ethical issues.

1. Subjects

The subjects of this study were three classmates of the researcher when studying for master degree in College of International Studies, Yangzhou University majoring in English Language and Literature. They have all successfully passed Advanced Interpretation Test. They were selected by purposive sampling. For the convenience of the research, they were labeled as S1, S2 and S3.

a. Background information of the subjects

Taking full advantage of various activities, S1 greatly improves her English fluency and accuracy. She was the winner of the Second Class Award in the Jiangsu Provincial Final of the 2010 "FLTRP Cup" English Public Speaking Contest, which not only enhances her writing skills but also quickens her immediate reaction to express herself in English. What's more, she was the English hostess of the performance presented by American Exaltation Ballet troupe in June, 7th, 2011, in which she interpreted the American leader's introductions to every program related with ballet history and religious stories. And she has visited America under the arrangement of Hanban for cultural communication in 2011. She played the role of an English hostess of the performance named "Melody of Spring" in Confucius Institutes in Atlanta, Memphis and Kentucky, as well as a lecturer of "Chinese Spring Festival and Yangzhou Culture" in some local high schools. She passed Advanced Interpretation Test in 2007.

$\mathrm{S} 2$ is a very talented and diligent student. She got a high score in TOEFL when she was a freshman in college and passed Medium Interpretation Test two years later. She paid much attention to listening and speaking by attending several speech contests and playing an active role in English salons at school. She passed Advanced Interpretation Test in the first year of postgraduate program.

S3 attended a foreign language middle school in which the students have more access to communicate with native English speakers, thus he had a good grasp of English listening and speaking. He had a group of foreign friends and often hung out with them. He also passed Advanced Interpretation Test in the first year of MA program.

What's more, all of them had some experiences of playing roles as interpreters, which provided great opportunities for them to put their interpretation learning into practice. No wonder, their practicing experiences enabled what they shared with the researcher to be more persuasive.

b. Reasons for subject selection

They were chosen as the subjects of the study for the following reasons.

The first and the most important reason is that they have all passed Advanced Interpretation Test, which is one of the training programs for talents in short supply and is considered one of the most authoritative tests in examining the command of interpretation. Taking this into consideration, the three subjects were proved to be successful interpretation learners and showed great talents in interpretation.

What's more, they are all outgoing and cooperative, which helped researcher smoothly conduct the interview as they were willing to share their learning experiences and would talk whatever they thought of without reservation.

In addition, all the three subjects were classmates of the researcher, not to mention that one of them was her roommate. They often studied in school library together, exchanging their ideas and discussing some academic controversies with each other. Their intimate relationship with the researcher guaranteed a harmonious and carefree atmosphere of the interview.

2. Instrument

The instrument of this study was the researcher herself.

Having never carried out a case study before, it was necessary for the researcher to get familiar with the theories and procedures of qualitative research by means of reading relevant books and journals on the subject in order to get a general knowledge of how to carry out interviews. Besides, she discussed with her supervisor regularly to gain some opinions on the interview details.

To get acquaintance with the whole procedure of an interview and to make sure that the interview could be carried out smoothly, the researcher conducted a pilot study before the formal interview by interviewing one of her roommates on the topic of "how to improve oral English", after which the researcher found out two problems. The first was that the researcher herself talked too much rather than encouraging the interviewee to talk about her experience, opinions and knowledge on the topic. The second was that some of the questions she raised were too vague, which gave little access 
for the interviewee to provide detailed information. Although the pilot study could not be considered as a successful one, it enabled the researcher to anticipate the potential problems so as to take them into consideration beforehand.

In addition, the researcher prepared a computer and a microphone to record the interviews for future analysis.

3. Interview guide

In order to probe into interpretation learning strategies thoroughly and comprehensively, the researcher prepared an interview guide in accordance with the dimensions that the research questions covered, which was categorized on the basis of Bao's criteria of interpretation, that is, completeness, accuracy and fluency of interpretation, in which completeness of interpretation is the focus of the study. To encourage the interviewees to produce more information, the researcher prepared the interview guide involving the following tasks: (1) decide the type of information; (2) determine the sequence of questions; (3) choose the wording of questions.

The interview guide covered the following types of information: the background of interviewees on learning English and interpretation, their knowledge and abilities on interpretation learning, their experiences of learning, their feelings while learning and their opinions on interpretation learning.

On the sequence of questions, the researcher first asked some warming up questions and got some information about interviewees' learning background. Then the researcher asked some questions probing into the interpretation learning strategies they employed to achieve the completeness of interpretation.

On the wording of questions, mostly the researcher asked open-ended questions to get the interviewees to talk about their experiences, feelings, opinions and knowledge of interpretation learning, and avoided presupposing which dimension of feeling or thought will be salient for the interviewees. For example, what will you do if you come across some unknown expressions while interpreting?

4. Data collection

Considering that the formal interview would last for too long based on the pilot study and that their opinions might be mutually influenced if the three subjects were interviewed at the same time, three interviews were conducted respectively.

All the three interviews were conducted in Chinese rather than English for the purpose of having smooth conversation and avoiding language obstruction and possible misunderstanding. A conversational style of interview kept the researcher and interviewees talking in a natural manner, which guaranteed the whole interviews going pleasantly and harmoniously. For each interview the researcher used a laptop and a microphone to record the whole process with the permission of the three subjects.

5. Data analysis

The whole data analysis involved three steps: coding, summarization and translation.

Step 1. Coding. The researcher first applied a set of codes to the specific and related information that interviewees provided in recorded data, with each code standing for a certain piece of information, just naming a few, $B J J Y$ representing note-taking strategy while $L J F X$ standing for logical analysis training strategy, etc.

Step 2. Summarization. By examining and comparing every piece of information in the whole set of data, the researcher looked for similarities and differences. Based on similarities, concepts were identified and further classified into categories. It seemed difficult to group all those codes at first, the researcher put aside the provisional codes and several days later reexamined the same data with a fresh mind. By repeating this process, she turned the data upside down and inside out to put them into categories, in which information on strategies of completeness of interpretation was gathered for analysis.

Step 3. Translation. Since the interviews were conducted in Chinese, it was necessary to translate all the relevant information into English. In order to make sure that the translation was accurate, the researcher asked one of her postgraduate classmate to help check the English version.

\section{RESUlts AND DisCUSSION}

In this section, it states four learning strategies employed by the three students to achieve the completeness of interpretation, namely knowledge-accumulation strategy, summarization strategy, note-taking strategy and logical-analysis strategy. Based on the interviews, most of these learning strategies are widely used while how they are employed differs from person to person.

\section{A. Knowledge-accumulation Strategy}

$\mathrm{S} 1, \mathrm{~S} 2$ and S3 all took this strategy as a preparation for interpretation while they had different focuses. S1 learned language knowledge and world knowledge in a comprehensive way; S2 seized every opportunity to obtain general knowledge and she also emphasized the primary role of language proficiency; S3 got help from TV and developed a habit of taking notes while watching.

S1: As to the general knowledge, the interpreter should be equipped with the language knowledge and world knowledge in a comprehensive way.

In order to master a language, we have to know well about various aspects of the language, besides linguistic knowledge, other knowledge related to the language should also be taken into consideration, including the evolvement history, language custom, literal works, proverbs, etc. A feasible way to improve linguistic proficiency is to read as 
much as possible in foreign language, which is a very important link to improve integrated language abilities. I chose materials that were not too difficult, otherwise it was easy to lose interests and produce resistance. When encountering with unfamiliar words, I looked up in English-English dictionary to cultivate the habit of English thinking. If things go on like this, I'm sure that everyone can build up a large vocabulary.

In terms of world knowledge, I think the best and the most convenient way is to surf the Internet. I concerned about the politic, economic and social news most, and the first website I visited every day is website of Tencent news by which I could keep a close contact with current international affairs.

S2 seized every opportunity to gain knowledge, and she agreed with S1 that she emphasized the primary and significant role of bilingual proficiency in interpretation learning.

S2: I suppose that an excellent interpreter should be knowledgeable, and to achieve this goal, one needs to accumulate varies of knowledge at ordinary times and be good at obtaining it in all kinds of ways and accesses. Listening to the broadcasts and tapes, reading journals and books, watching movies and TV programs and surfing the Internet, they are all ways to learn. Every day, new things come up, together with which are new words and expressions. We ought to develop a habit of learning at anywhere anytime. And this is really what I did in my daily learning.

There is also one thing I would like to mention that interpretation is a process of exchanging information between two languages. Thus, bilingual proficiency, especially English, is no doubt the foundation of interpretation learning, and one cannot interpret well until he has a good grasp of English.

S3 took a different access to obtain general knowledge. He watched English television channel CCTV NEWS every evening, which he considered as a two-birds-with-one-stone way to learn both general knowledge and updated words and expressions to improve English proficiency.

S3: I had a habit of watching CCTV NEWS for a very long time and benefited a lot from it. Every time I watched this channel, I would take out a little notebook labeled as "for news words". When I encountered some popular and updated words and expressions, such as "accredited journalist", "overwhelming majority", "Pentagon", etc., I took them down in this little notebook and reviewed them in a regular time. At first, I might not understand what I was listening to, for the news was too politic or economic, but as time went on and as my accumulated vocabulary became larger and larger, I made it, finally.

\section{B. Summarization Strategy}

To achieve the completeness of interpretation, all of the three students employed summarization strategy, and they share something in common: focusing on meaning rather than language itself.

S1 supposed that focusing on meaning is the key to the success of interpretation learning and news is no doubt a good learning material. The following quotes show how she employed this strategy specifically.

S1: the purpose of summarization is to focus on the meaning rather than language itself while listening, which, I suppose, is the key to the success of interpretation learning. After listening to a speech, I tried to concentrate on the meaning of the information to forget language subconsciously. Focusing on meaning helped me ignore the language the speaker used and visualize the information, which reduced the burden of memory because memorizing meaning is easier than memorizing vocabulary. For example, when describing a house, I would visualize the layout or the surroundings of the house to help me memorize the information. That is to say, in order to summarize the content of a given listening material, the listener must active mentally organize the information he's receiving. To do this, he must get the main idea, which means drawing main idea from secondary ideas and relevant from irrelevant information. As for listening materials, most of the topics on BBC and VOA are suitable, and apart from these, TV interviews, debates and dialogues could also be the materials of making summarization due to the fact that everyone's speech could be taken as independent contents which convey completed meaning of what the speaker wants to share. What's more, these listening materials could also widen your horizon and help get familiar with some cultural and technical expressions, which in turn will facilitate your summarization.

This is an example of applying summarization strategy given by $\mathrm{S} 1$ :

"During the past 10 dismal years of American decline, few sights have been more pathetic than that of a succession of U.S. Treasury secretaries traveling to foreign cities, cap in hand, to beg the Chinese to stop being so mean to our economy.

It has reminded me of nothing so much as the infamous footage of Neville Chamberlain, then the first minister of the world's greatest empire, flying as a supplicant to Berchtesgaden during the Munich crisis.

We now look like the British Empire near its end.

Witness the G-20 meeting this weekend. It produced yet more pious words about China's predatory currency manipulation, but nothing of substance. Another meeting is scheduled for next month, from which we probably can expect yet more pious words.

As for the suggestion that China will work to lower its gigantic trade surplus, analysts at GaveKal, a research firm in Hong Kong, have the takedown: 'If, as Beijing recently proposed, it takes the country about four years to get the current account surplus back down below 4\% of GDP (where it last was in 2004), ' they write, 'then assuming nominal GDP growth of $11 \%$, a further $\$ 100$ billion will actually be added to the surplus. That brings it to $\$ 400$ billion by 2014 , higher than the peak level of 2007 and six times the level of 2004. In other words, China will still be demanding a lot of excess demand from the rest of the world." (Excerpt from BBC News 2010, 11, 4) 
S1's summarization goes as follows:

“美国在过去十年总是到国外去请求中国人不要对我们的经济这么文音。这周末的 $G 20$ 会议对中国汇率操纵 问题也没提什么实质性内容，对于中国将采取措施降低其巨额贸易顺差的说法，香港分析师认为中国将需要其 他国家的需求进一步大幅提高。”

S2 did not mean to take summarization as a learning strategy of interpretation at first, but it turned out to prepare her for the following steps of interpretation learning. She also stressed the importance of focusing on meaning or the content of the article and gave some suggestions for summarization which is reflected in the following quotes.

I did not learn this strategy on purpose. It became one of my training programs just when I fail to retell a short article with a summarization. So I thought that maybe I should start with summarization and move to retelling part when I was ready. It was proved that I did right. Summarization made me prepared for the next step of interpretation learning. And for summarization, I want to say that Rome was not built in a day, and you need to practice thousands of times with passages with different topics, in different language styles, and of different genres. Focus should be put on understanding and summarizing the meaning of the contents rather than overemphasizing the language issues. You only need to summarize the main content of the given speech at the very beginning, and add more with what you can memorize after you have mastered summarization strategy.

S3 gave some principles while doing summarization: summarizing in Chinese, no note taking and no word consulting. The following quotes show his principles in details.

S3: I presume that most of us has done summarization, no matter in reading class or interpretation class, and we are all very familiar with what it was about. However, to guarantee the achievement of the purpose, I think there are some notes should be attached great importance to:

First, summarize the main content of the listening materials in Chinese rather than English because we tend to repeat what the speaker said word by word if using English. Second, no notes should be taken in summarization, let alone numbers and proper words. Third, when coming across some new words, you ought to guess the meaning according to the context instead of looking up the dictionary or asking for somebody else. If it is really difficult and necessary to know the exact meaning, you could deal with it after summarization.

\section{Note-taking Strategy}

The three subjects believe that this strategy is the most essential one in interpretation learning strategies and all of them did a lot of practice and worked out their own way of note-taking.

S1 always has her own learning methods and she is very good at thinking and summarizing at every step of her learning process. On note-taking, she gave us some tips: write as few words as possible; take notes in target language; take notes logically and legibly. The following quotes are her experience she is willing to share on note-taking learning strategy.

S1: I really have some experience to share because I do practice a lot in note-taking and find my own way to operate effectively. Here are some tips I would like to share with you.

First, write as few words or symbols as possible. I always concentrated on listening. And, as time was limited in interpreting, I practiced the maximum economy in words in note-taking. Each word or symbol usually represented a key word or a sense group, etc.

Second, it is better to take notes in target language. In order to facilitate the listening-transference-speaking process, I supposed it was preferable to solve the problem of transference while the notes were taken.

Third, see to it that the notes are logical and legible. Just as what I have said, I practice doing logical analysis to make sure that I have a clear grasp of the speech and take notes accordingly. In this way, the speaker's flow or sequence of ideas can be better grasped and noted and therefore better interpreted. At the same time, make sure that the notes are easy to read. I wrote notes in two columns of 2 or 3-inch width in a pad and drew two slant lines to mark the end of a long paragraph, or a long chunk of speech, to avoid some unnecessary confusion. For the sake of legibility, I use only limited number of signs or symbols that are very familiar to me lest I might forget their meanings if I uses too many a time. Possible examples are acronyms, abbreviations, arrows, and reference lines.

There is an easy example of my note-taking: China is exporting different products to different parts of the world, such as clothes, shoes, and hats to Europe and corn, oats, wheat and barley to Africa.

Notes can be demonstrated as:

Clothes shoe hat $\rightarrow E U$

corn oat wheat barley $\rightarrow$ Afri

S2 gave us a systematic direction on what to note, how much should be noted, what language we should take, and what kinds of signs and symbols should be memorized. The following quotes illustrate her learning strategy of note-taking.

S2: At the very beginning of practicing, I totally concentrated on note-taking ignoring the analysis and organization of information which led to the fact that I relied too much on the notes in interpreting, and made them the block stone of my understanding and expressing. Therefore, memorize the information with brain and take notes as supplement only. Thus, you need to get well prepared with summarization.

On what to note, I think figures, technical terms, proper nouns, listed words, key words that represent the central 
meanings and thoughts of what the speaker trying to express and words which seem simple yet are easily forgotten should be counted. Besides, tenses, voices and conjunctions should also be noted, which are extremely important to the logic of the output of interpreting.

On how much should we note, I have to say there is no standard that fits all. If you ask me how long should we note compared to the speech, I am saying that the better you understand the speech, the less you would rely on the notes. In other words, if you understand the speech well, even it is long, you only need to note several words; on the contrary, if you know little about the speech, even it is short, you have to note more. How much we should note depends on the logic of the speech, the topic and interpreter's knowledge about the content.

Then what language should we take? Basically, target language provides convenience to the output of interpretation. Interpreters could choose the quicker and easier way to note according to the actual situation. For example, when doing Chinese to foreign language interpretation, Chinese is shorter than foreign language and Chinese is mother tongue, then we could note in Chinese; on the contrary, if taking notes in foreign language is easier than in Chinese, we use foreign language.

Concerning signs, symbols and abbreviations, remember those that are commonly and frequently used and familiar

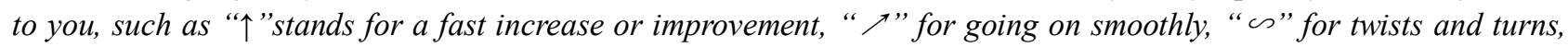
“】” for slow progress, “ :" for thinking, and "?” for questioning. I don't recommend you to memorize too many signs, symbols and abbreviations which would confuse you at the very moment of interpreting and get you into trouble. What I would like to mention in particular is that the first and the last sentences of the speech should be noted. The purpose of noting the first sentence lies in that interpreters could start interpreting right after the speaker finished his first unit of speech and noting the last sentence makes sure that the audiences know that it is the end of the former speech.

S3 didn't catch the essential of taking notes at first. She took it for granted and thought that it was no big deal, so she failed at first. He gave us some suggestions on how to take notes and what should be noticed in the process of note-taking learning. The following quotes show exactly what he meant.

S3: Note-taking is supposed to release the burden of memory in interpreting, while what it came to me is totally an excess burden itself at first. I could not help noting all the information I heard word for word and sentence for sentence as I was doing dictation, which of course led to the fact that I forgot what was next. Sometimes I just didn't know where to start noting, and although I understood what I heard, I forgot them all in the next second. That was really frustrating. So note-taking is a strategy that you need to learn and practice with a large amount of time and energy. It is not as easy as what it seems to be.

There are two disciplines you have to remember. First, the purpose of note-taking in interpreting is to supplement memory efficiency, so as to ensure completeness of interpretation. This means, though highly necessary, the importance of note-taking should not be overemphasized. You must realize that it is always memory that plays the major role in ensuring completeness in interpreting, not note-taking. Second, the interpreter's notes are essentially individual in character. The ability to keep remembrance of what is said varies from person to person. So you need to find your own way of taking notes after reference to other's experience. What's more, there's no need to memorize all those signs and symbols you have met, and only those that you are familiar with and that appear frequently are worth memorizing.

\section{Logical-analysis Strategy}

S2 is a girl who knows herself well. She knows exactly where she is and where she is to go. In her process of interpretation learning, she found that although she could take down the main points of information while listening, she could not figure out what the relations between them. So she employed logical-analysis strategy.

S2: when doing logical analysis, I chose authentic speech scripts which had a clear structure and simple language without many rhetoric expressions and avoided those literary works which emphasized some emotional, artistic, and imaginative literal effects. Then I usually set a time limit of 2 minutes to analyze the logical relations of the scripts quickly and briefly. I marked the main points of the information directly on the scripts, and marked the logical relation----whether it is paralleled or progressive or it is a turning point----of the main points in the blank space of the scripts using symbols like arrowhead or dash, etc. The last step was to retell the main points and logical relations between them in my own word.

There are three points you need to keep in mind in doing this: first, the exact scripts are not easy to find because most of the speakers are not so orderly and coherently doing their speech and there may be ambiguous wording, vague expressions and unorganized structure. In that case, we could first rewrite those illogical and unstructured scripts into logical and structured ones, which is also a good way to do logical analysis. Second, the main points are usually those content words without which the meaning of the scripts are not complete and clear. That is to say, pick the key and crucial information points and do not mark too much unrelated information to avoid increasing the burden of thinking. Third, do not retell in target language at the very beginning, which will bring you the sense of frustration as you have to translate when structuring the logical relation of the scripts. Even in source language, do not require retelling completely and meticulously like what a professional interpreter does, what matters is that the structure is distinct, the logical relations are clear and the turning points are evident.

\section{CONCLUSION}


It is drawn from the above results that, to achieve the completeness of interpretation, they employed knowledge-accumulation, summarization, note-taking and logical-analysis learning strategies, among which the first three strategies are all employed by the three subjects. To accumulate knowledge, they gained access to Internet, TV, broadcasts, journals and books. It indicates that in the process of interpretation learning, they all give priority to content or meaning over form or language, which is consistent with hermeneutical idea of interpretation. Gardamer (1975) believes that interpretation's task is to interpret the intentions and thoughts, as well as the cultures of source languages, which is just the aim of summarization strategy they employed and what the three successful interpretation learners put great emphasis on. When it comes to note-taking, it is boiled down to shorthand: shorthand in words and phrases, shorthand in symbols and signs and shorthand in numbers. Logical analysis is a unique strategy to help better understand the structure and logic of the original scripts.

What is worth mentioning is that they all believe bilingual proficiency comes before learning strategies to achieve successful interpretation, and they consider it as the foundation of interpretation learning. This finding shows that learning strategies are not everything, which we should not be over-dependent on. To improve and polish their English proficiency, they keep on doing some reading, writing, listening and speaking in their routine studies. As for Chinese, their mother tongue, they read some newspapers, commentaries and even novels before they go to bed.

All in all, this thesis is only a tentative probe into the interpretation learning strategies employed by successful interpretation learners. Due to the insufficiency of the author's knowledge, this thesis leaves much to be desired. It's the author's wish that more relevant empirical studies be pursued in order that we can testify the effectiveness of the strategies and provide more enlightening information about the interpretation learning strategies.

APPENDIX

访谈提纲

英语学习背景调查

1. 你从什么时候开始学习英语的? 学了多少年了? 刚刚接触英语的时候你对英语是什么感受呢?

2. 为什么选择英语作为自己的专业? 是你自己的兴趣爱好还是你父母的意见呢? 或者觉得英语专业热门将来 好找工作? 你有出国的打算和计划么?

3. 初入扬州大学时, 你有没有制定过某些个人学习和发展的计划或者规划? 能详细一点说明么?

4. 针对上一个问题进一步追问: 在大学学习生活中, 有没有按照既定的计划去指导你的学习?

5. 在各门专业课中, 你最感兴趣的是哪些? 精读, 泛读, 听力, 语法, 口语, 口译还是其他?

6. 在各门专业课中, 你认为对你帮助最大的是哪些? 精读, 泛读, 听力, 语法, 口语, 口译还是其他?

7. 你认为自己的英语水平怎样? 参加过什么比赛或考试?

8. 为什么想考高级口译? 觉得口译难吗?

9. 考口译的时候英语什么水平? 你认为要想通过英语高级口译考试或成为一名专业的译员, 英语至少要达到 什么水平?

如何提高口译的完整性?

1. 第一次口译练习是什么样子的?

2. 听的时候遇到哪些困难? 因为什么听不懂呢? 内容不了解? 说话人话语有地方口音? 环境嘈杂?

3. 平时如何进行听辨练习? 有没有什么方法?

4. 你有没有因为一次性听的信息量过多而遗忘? 你用什么办法克服的呢?

5. 如果口译的句子或段落很长, 你如何使得语言表达比较有条理, 语义层次分明? 平时怎么训练呢?

6. 在平时的听辨练习中, 感觉自己的听力水平有提高吗? 如何提高的呢? 和平时听力课堂上或听力考试中的 听力方法有没有不同? 什么地方不同?

7. 在平时的训练和提高中, 课堂上老师教授的一些知识和技巧能用到吗? 有哪些技巧比较有效?

8. 我们常常会遇到一个问题, 刚开始练习口译的时候可能即便听懂了也不能表达完全, 你是如何进行针对练 习的? 一开始会用原语进行复述吗? 有没有效果?

9. 你认为百科知识对口译的理解重要吗? 你是通过哪些途径获取百科知识的? 哪一类的百科知识是你学习 的重点?

\section{REFERENCES}

[1] Bao Gang. (2005).Interpretation Studies: An overview on Interpretation Theories. Beijing: China Translation \& Publishing Corporation.

[2] Chen Jing. (2002). Fundamental Considerations in Interpreting Testing. Chinese Translators Journal (1): 51-53.

[3] Gadamer, H. G. (1975). Truth and method. New York: The Continuum Publishing Co.

[4] Gao Liang, Lin Yuru. (1996). A Textbook of Interpretation. Fuzhou: Fujian People's Publishing House.

[5] Hua Yun. (2002). Fumble in Practice and Develop in Innovation. Exploring Education Development (9), 54-59.

[6] Lei Jing. (2011). Conceptual Dimension Construction and Empirical Assessment of Learning Strategy for Interpreting. Journal of Guangxi University for Nationalities 33(1): 181-185. 
[7] Li Sainan. (2013). The current Situation, Problems and Outlooks of Interpreting Strategies Research in China. Journal of Inner Mongolia Agricultural University (2): 110-114.

[8] Liu Heping. (2005). Interpretation Skills_— The Science of Thinking and Reasoning Method of Interpreting Teaching. Beijing: China Translation \& Publishing Corporation

[9] Ren Wen. (2009). A Coursebook of Consecutive Interpreting. Beijing: Foreign Language Teaching and Research Press.

[10] Xie Hong. (2001). An Upsurge for Interpretation. Growth and Employment (4): 51-52.

[11] Yang Chengshu. (2005). Interpretation Studies: Theory and practice. Beijing: China Translation \& Publishing Corporation.

[12] Yang Qing. (2006). A Case Study of the Effectiveness of Interpretation Learning Strategies. MA thesis. Wuhan: Donghua University.

[13] Zheng Zhihua. (2004). On Interpretation Learning Strategies---From the Perspective of Learning Strategies in SLA MA thesis. Chengdu: Sichuan University.

Sainan Li was born in Hebei, China in 1984. She received her MA Degree in School of Foreign Language from Yangzhou University, China in 2012.

She is currently a teacher of Faculty of Foreign Languages of Huaiyin institute of Techonology, Jiangsu, China. She majors in Linguistics and English Literature. 